\title{
Claudio Ciborra and the information systems field: legacy and development
}

Journal of Information Technology (2006) 21, 127-128. doi:10.1057/palgrave.jit.2000061

\section{$\mathbf{T}$ \\ $\mathbf{T}$} pecial Issue Editorial September 2006 he recent untimely death of Professor Claudio Ciborra in February 2005 raises the question: how can his major contribution to the Information Systems (IS) field be consolidated, celebrated and progressed? His passing was honoured with many personal reminiscences and assessments of his contribution in a special issue of The European Journal of Information Systems (Volume 14 No. 5, 2005). In planning the present Special Issue we intended to take this further, and to consolidate and progress Claudio's contribution by commissioning detailed research papers influenced by but developing further his work.

In ideas and research Claudio was a polymath but also worked in a mainstream European philosophical tradition. At home in the world of Husserl and Heidegger, he could trade ideas with anyone, and could embrace Williamson's work on Transaction Cost Economics as equally well as the work of Polanyi and Nietzche. Improvisation, innovation and critique were words he frequently used. His book The Labyrinths of Information shows the breadth and depth of the ideas he drew upon. A critique of the IS field, it is organised around Krisis, Bricolage, Gestell, Derive, Xenia, Shi, Kairos and Affectio. His work and interests are also well represented in three collected volumes: Teams Markets and Systems (Cambridge: CUP 1993), From Control To Drift: The Dynamics of Corporate Infrastructures (Oxford: OUP 2001), and The Social Study Of Information and Communication Technologies (Oxford: OUP 2004)

Claudio built up a formidable legacy in a field somewhat short of new ideas, methods and directions, let alone philosophical underpinnings. For this special issue we offer a new, unpublished work by him in the form of the first paper The Mind or The Heart: It Depends on (The Definition Of) Situation. This work captures the essential thrust of Claudio's intent - challenging, thoughtful, well researched, embracing ideas, critical and seeking to move the IS field on, into new territory and new understandings.

In this he set a benchmark for our choice of papers. We received twenty submissions, each of which had three referees, and in the end, after a series of paper revisions and difficult choices, we narrowed it down to seven further publishable papers. Some other papers that could not be made ready in time against the tight deadline for this Special Issue would be considered for a more extensive book we are scheduling, and indeed we would like to take this opportunity to invite further contributions to that volume. Interested parties should contact one of the Special Issue editors as listed below, in the first instance.
In this present issue two papers elaborate on Ciborra's phenomenological perspective of IS and its explanatory strengths. In Hospitality, Improvisation and Gestell: A Phenomenology of Mobile Information, Martin Brigham and Lucas Introna provide a clear presentation of these three concepts and demonstrate the way they can enhance our understanding of IS and organisational change by using them to examine changes that occurred in the practice of a fire brigade in the UK when they started using mobile data systems. In The Hospitality Metaphor as a Theoretical Lens to Understand the Process of ICT Adoption Saccol and Reinhard discuss 'hospitality' as a new approach for ICT adoption that departs from positivist models. They trace the philosophical origins of this metaphor and its emergence in the IS field mainly through Ciborra's work and they apply it to gain insights on a case study of a Brazilian Bank that equipped its employees with mobile technology.

Amany Elbanna's paper The Validity of the Improvisation Argument in the Implementation of Rigid Technology: The Case of ERP Systems draws on Ciborra's work on improvisation and drift. She examines whether these concepts are relevant and valid for ERP projects, which are generally understood as rigid and therefore in need of careful planning. She combines Ciborra's ideas with an Actor Network Theory (ANT) analysis to argue that improvisation, bricolage and drift are constituent processes of highly structured projects of rigid technology.

Edgar Whitley and Mary Darking, in Object Lessons and Invisible Technologies examine the nature of technology artefacts - a longstanding theme in IS research - by contrasting ideas stemming from recent research in the ANT perspective and Ciborra's phenomenology. They use a European Union project that aims at developing a new technological infrastructure to demonstrate the explanatory capacity of these perspectives and emphasise the significance of the concept of Gestell that Ciborra drew from Heidegger.

Petter Nielsen and Marguun Aanestad in Control Devolution as Information Infrastructure Design Strategy: A Case Study of a Content Service Platform for Mobile Phones in Norway draw on Ciborra's critical writings on control in IS development and the development of ICT infrastructures. They focus on the control $v s$ autonomy choices made in the process of the development of an infrastructure for mobile content by two Notwegian operators. They argue for 'control devolution' as a successful strategy that should be followed by the industry 
in order to address risks in infrastructure projects and maintain innovative capacity.

Antonio Cordella's article Transaction Costs and Information Systems: Does IT Add Up? builds on Ciborra's work on transaction costs economics, which was among the earliest efforts to sensitise the IS field on the way ICT affects information aspects of economic exchange. Following this path of thought Cordella discusses the effects of ICT in terms of the interdependences of the factors contributing to transaction costs.

Finally, in Knowledge: Climbing The Learning Ladder to A 'Phenomenological' View Andrea Resca points out that questions of epistemology have been a constant preoccupation in Ciborra's work, from his writings on transaction costs to his phenomenological analyses. He thus traces the thread that connects his analyses of knowledge and rationality in economic and administrative behaviour, of knowledge, learning and organisational strategy, and of improvisation and situated action.

Chrisanthi Avgerou ${ }^{1}$, Ole Hanseth ${ }^{2}$ and Leslie Willcocks ${ }^{1}$ ${ }^{1}$ London School of Economics, London, UK ${ }^{2}$ University of Oslo, Blindern, Oslo 